\title{
Penggunaan Metode Picture and picture untuk Meningkatkan Keterampilan Berbicara (Materi Dongeng) pada Anak Sekolah Dasar
}

\section{Elin Rosmaya}

Prodi Diksatrasia, Universitas Swadaya Gunung Jati; elin.unswagati@gmail.com

\begin{abstract}
Abstrak. Urutan keterampilan berbahasa yang diperoleh anak secara berurutan dimulai dari keterampilan menyimak, keterampilan berbicara, keterampilan membaca dan keterampilan menulis. Pada keterampilan berbicara ini, anak yang menggunakan bahasa daerah sebagai bahasa ibu merasa kesulitan berbicara menggunakan bahasa indonesia sebagai bahasa nasional dan bahasa negaranya. Kecanggungan dan rasa tidak percaya diri merupakan faktor utama anak daerah kesulitan berbicara di depan umum menggunakan bahasa Indonesia dengan memperhatikan faktor kebahasaan yang tepat. Hal ini juga menjadi permasalahan yang dikeluhkan guru SDN I dan SDN II Ciparay Kecamatan Leuwimunding kabupaten Majalengka. Untuk itu, penulis melakukan penelitian dengan judul "Penggunaan Metode Picture and picture untuk Meningkatkan Keterampilan Berbicara (Materi Dongeng) Pada Anak sekolah Dasar." Tujuan penelitian ini adalah untuk mengetahui penggunaan metode picture and picture dalam meningkatkan keterampilan berbicara anak di kelas III dan untuk mengetahui keefektifan metode picture and picture dalam meningkatkan keterampilan berbicara anak. Berdasarkan penelitian, diperoleh hasil bahwa siswa yang menggunakan metode picture and picture dapat dengan mudah menceritakan kembali dan mengungkapkan pesan dongeng dibandingkan dengan yang menggunakan metode snowball throwing. Hal ini menunjukan bahwa metode picture and picture dapat meningkatkan kemampuan keterampilan berbicara anak SD terutama materi mengungkapkan pesan dongeng menggunakan kosakata baru dan kalimat efektif.
\end{abstract}

Kata Kunci : Picture and picture, Keterampilan Berbicara

Abstract. The child order languange skills are obtained in sequence from observe attentively, speaking, reading, and writing skills. In this speaking skill, the child that speaks using local languange as their mother languange are difficulty speak using Bahasa Indonesia as National Languange. Awkwardness dan not confidence are the main factor for local child to speak Bahasa Indonesia with the right languange in public. This was the problems that teachers of SDN I and II Ciparay, Kabupaten Majalengka complained about. So that, writers conduct research about "The Using of Picture and picture Method to Improve Speaking Skill (at Fairytale matter) in Primary Student. This research aim is to know the effectiveness and the using of picture dan picture method in improving grade III students speaking skill. Based on research results, it was obtained that students who has used picture and picture method are more easily recounted and reveal a fairytale message than those who used snowball throwing method. This shows that picture and picture method can improve

Caruban: Jurnal Ilmiah Pendidikan Dasar 3(1), 67-76, Januari 2020

DOI: http://dx.doi.org/10.33603/.v3i1.3189, p-ISSN 2615-1391, e-ISSN 2620-3219

CProdi PGSD Universitas Swadaya Gunung Jati 
primary students speaking skill especially at reveal fairytale using new vocabulary and effective sentence matters.

Keywords: Picture and picture method, Speaking skill

\section{Pendahuluan}

Keterampilan berbahasa memiliki empat komponen yang satu sama lainnya memiliki hubungan yang sangat erat. Keempat komponen berbahasa tersebut adalah keterampilan menyimak, keterampilan berbicara, keterampilan membaca dan keterampilan menulis (Nida, Harris, dalam Tarigan, 1990). Empat keterampilan berbahasa tersebut tidak didapatkan secara alamiah namun didapatkan melalui proses belajar yang bertahap. Keterampilan berbicara merupakan keterampilan berbahasa kedua yang didapatkan manusia setelah keterampilan menyimak. Sementara itu, menurut Haryadi (1994) ada beberapa fungsi berbicara. Berbicara dalam kehidupan dapat berfungsi sebagai 1) pemenuhan hajat/kebutuhan hidup manusia sebagai makhluk social dalam masyarakat; 2) alat komunikasi untuk berbagai urusan atau keperluan dalam hidupnya; 3) ekspresi sikap, perasaan dan nilai demokrasi; 4) alat pengembangan dan penyebarluasan ide/pengetahuan; 5) peredam ketegangan, kecemasan dan kesedihan.

Pada keterampilan berbicara ini, anak belajar menggunakan bahasa sesuai dengan bahasa ibunya (bahasa pertama yang digunakan sehari-hari di lingkungan keluarga). Perlu diketahui bahwa Indonesia merupakan salah satu negara yang memiliki lebih dari tujuh ratus bahasa daerah yang disatukan oleh bahasa persatuan yaitu bahasa Indonesia. Banyaknya bahasa daerah yang dimiliki negara ini, menunjukkan bahwa rata-rata penduduk Indonesia menguasai dua bahasa, yakni bahasa ibu/bahasa daerah dan bahasa kedua/bahasa Indonesia. Hal ini merupakan sebuah kebanggaan tersendiri bagi rakyat Indonesia karena menunjukkan kekayaan bahasa yang dimiliki negara Indonesia. Tindakan mengenalkan bahasa daerah sebagai bahasa yang diajarkan pertama kali dalam berbicara, merupakan salah satu upaya melestarikan bahasa daerah.

Namun demikinan terdapat permasalahan lain yang didapatkan anak pada saat beralih bahasa. Terutama pada saat berbicara di depan umum menggunakan bahasa Indonesia sebagai bahasa pengantar dalam dunia

Caruban: Jurnal Ilmiah Pendidikan Dasar 3(1), 67-76, Januari 2020

DOI: http://dx.doi.org/10.33603/.v3i1.3189, p-ISSN 2615-1391, e-ISSN 2620-3219

(CProdi PGSD Universitas Swadaya Gunung Jati 
pendidikan. Anak yang tidak biasa menggunakan bahasa Indonesia sebagai bahasa sehari-hari merasa sungkan dan ragu ketika disuruh berbicara di depan umum menggunakan bahasa indonesia. Keterampilan berbicara diperlukan sebagai alat menyatakan pendapat, gagasan, memberi informasi atau menerima informasi. Kegitan tersebut biasanya dilakukan pada lingkungan dan situasi resmi/formal dengan menggunaan bahasa Indonesia. Untuk itu, membiasakan anak terampil berbicara di depan umum sejak dini sangat diperlukan agar anak berani berpendapat dan percaya diri mengemukakan gagasannya. Faktor kebahasaan seperti ketepatan ucapan (tata bunyi), penempatan tekanan, nada, sendi, dan durasi yang sesuai, pilihan kata (diksi), dan kalimat efektif sangat penting sebagai penunjang keterampilan berbicara seseorang. Dalam hubungannya dengan tata bunyi, seorang yang terampil berbicara menggunakan bahasa Indonesia harus bisa berbicara tanpa menggunakan dialek atau logat daerah.

Banyaknya permasalahan keterampilan berbicara yang dihadapi anak (terutama anak dengan latar belakang berbahasa daerah) ini diketahui berdasarkan pengalaman yang dibagi teman-teman guru di SD 1 dan SD 2 Ciparay Leuwimunding. Guru mengeluhkan anak didiknya yang malu dan tidak percaya diri ketika harus berbicara di depan umum menggunakan bahasa Indonesia. Bahkan untuk sekadar berkomunikasi menggunakan bahasa Indonesia saja anak-anak merasa canggung. Hal ini menyulitkan guru untuk mengembangkan bakat anak pada saat lomba di kabupaten atau di luar kabupaten. Dengan demikian dibutuhkan perlakuan yang tepat yang dapat mengatasi permasalahan tersebut. Salah satu upaya yang dapat dilakukan pendidik di lingkungan sekolah adalah melakukan kegiatan pembelajaran yang membiasakan anak-anak agar sering tampil berbicara di depan kelas. Selain itu perlu adanya upaya merangsang anak agar mau berbicara di depan kelas baik menggunakan media atau metode pembelajaran yang tepat.

Salah satu metode pembelajaran yang menawarkan metode sekaligus media adalah metode picture and picture. Berdasarkan teori Hamdani (2011 : 89), metode picture and picture ini menggunakan gambar yang diurutkan secara logis. Tujuan dari metode picture and picture ini adalah agar menjadikan pembelajaran lebih menarik dan menyenangkan bagi siswa, serta membuat

Caruban: Jurnal Ilmiah Pendidikan Dasar 3(1), 67-76, Januari 2020

DOI: http://dx.doi.org/10.33603/.v3i1.3189, p-ISSN 2615-1391, e-ISSN 2620-3219

(CProdi PGSD Universitas Swadaya Gunung Jati 
siswa aktif dalam pembelajaran. Penggunaan gambar dalam metode ini sekaligus dapat dijadikan media yang akan merangsang anak agar bertindak aktif di kelas. Siswa akan berlatih berbicara sesuai dengan gambar yang mereka urutkan. Untuk itu, penulis melakukan penelitian terhadap permasalahan berbicara ini. Penelitian dilakukan terhadap siswa SD kelas III SD I Ciparay dan kelas III SD 2 Ciparay. Penelitian dilakukan pada materi menguraikan dan memeragakan dongeng yang terdapat pada kompetensi dasar 3.8 dan 4.8 kelas III. Dongeng merupakan cerita yang berdasarkan pada angan-angan atau khayalan seseorang yang kemudian diceritakan secara turun temurun dari generasi ke generasi (Sugiarto, 2015 : 159). Materi ini berkaitan dengan keterampilan berbicara. Tabel 1 berikut merupakan uraian kompetensi dasar yang akan diterapkan.

Tabel 1 Kompetensi Dasar

\begin{tabular}{|c|c|c|}
\hline Kompetensi Dasar & Materi Pembelajaran & Kegiatan Pembelajaran \\
\hline $\begin{array}{lr}\text { 3.8 Menguraikan pesan } \\
\text { dalam dongeng yang } \\
\text { disajikan secara lisan, } \\
\text { tulis dan } & \text { visual } \\
\text { (gambar/film) dengan } \\
\text { tujuan } \\
\text { kesenangan }\end{array}$ & $\begin{array}{ll}\text { - } & \text { Teks dongeng } \\
\text { - } & \text { Ungkapan diri }\end{array}$ & 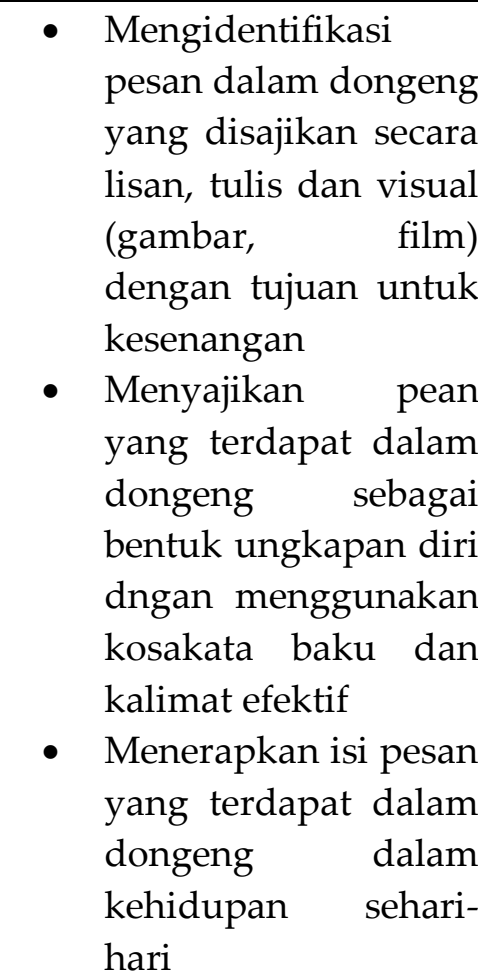 \\
\hline
\end{tabular}

Dari uraian materi yang akan diajarkan dapat diketahui bahwa materi dongeng di kelas III SD ini termasuk ke dalam kegiatan keterampilan berbicara. Terlebih lagi disebutkan dalam KD 4.8 bahwa siswa harus bisa memeragakan pesan dongeng menggunakan kosakata baru dan kalimat

Caruban: Jurnal Ilmiah Pendidikan Dasar 3(1), 67-76, Januari 2020

DOI: http://dx.doi.org/10.33603/.v3i1.3189, p-ISSN 2615-1391, e-ISSN 2620-3219

(CProdi PGSD Universitas Swadaya Gunung Jati 
efektif. Untuk itu dibutuhkan cara agar siswa bisa berbicara bahasa Indonesia menggunakan kosakata yang tepat dan kalimat yang efektif . Untuk itu, penulis mengambil judul penelitian Penggunaan Metode Picture and picture untuk Meningkatkan Keterampilan Berbicara pada Anak Sekolah Dasar. Adapun rumusan masalah dalam penelitian ini adalah (1) Bagaimana penggunaan metode picture and picture dalam meningkatkan keterampilan berbicara anak di kelas III? (2) Apakah penggunaan metode picture and picture dapat meningkatkan keterampilan berbicara anak di kelas?

\section{Metode}

Metode yang akan digunakan dalam penelitian ini adalah metode eksperimen karena pada metode penelitian eksperimen terdapat perlakuan (treatment) untuk mencari pengaruh perlakuan tertentu terhadap yang lain dalam kondisi yang terkendali. Menurut Sugiyono (2008 : 72), metode penelitian eksperimen adalah metode penelitian yang digunakan untuk mencari pengaruh perlakuan tertentu terhadap yang lain dalam kondisi yang terkendali. Penelitian ini dilakukan untuk mengetahui dan menyelidiki ada atau tidaknya perbedaan setelah adanya perlakuan yang berbeda terhadap kelompok eksperimen dan kelompok kontrol siswa SD yang melakukan kegiatan berbicara di depan umum. Dalam hal ini yang menjadi kelas eksperimen adalah siswa kelas III SDN 1 Ciparay yang berjumlah 25 orang. Sedangkan yang menjadi kelas kontrol adalah siswa kelas III SDN 2 Ciparay yang berjumlah 25 orang.

Kelompok eksperimen dalam penelitian adalah kelompok yang mendapat perlakuan khusus dalam kegiatan pembelajarannya yaitu mendapatkan metode picture and picture pada keterampilan berbicara sedangkan kelompok kontrol adalah kelas pembanding yang tidak mendapat perlakuan khusus tetapi mendapatkan metode snowball throwing. Untuk memperoleh data penelitian, peneliti melakukan pengumpulan data dengan menggunakan teknik nontes dan teknik tes. Pengumpulan data dengan teknik nontes dilakukan dengan observasi. Tahap observasi dilaksanakan dengan tujuan untuk mengetahui keadaan siswa selama proses pembelajaran.

Caruban: Jurnal Ilmiah Pendidikan Dasar 3(1), 67-76, Januari 2020

DOI: http://dx.doi.org/10.33603/.v3i1.3189, p-ISSN 2615-1391, e-ISSN 2620-3219

CProdi PGSD Universitas Swadaya Gunung Jati 


\section{Hasil dan Pembahasan}

Sebelum dilaksanakan pembelajaran, terlebih dahulu peneliti melakukan observasi terhadap kemampuan berbicara siswa di SD Ciparay I dan II. Observasi ini dilakukan untuk membuktikan hasil wawancara kami dengan guru-guru sebelumnya yang mengungkapkan bahwa siswa-siswanya kurang percaya diri dalam berbicara menggunakan bahasa Indonesia. Berdasarkan hasil pengamatan di sekolah dapat diketahui bahwa siswa SD Ciparay $100 \%$ menggunakan bahasa daerah untuk berkomunikasi dalam lingkungan sekolahnya di luar jam pelajaran. Sedangkan di dalam kelas, siswa menggunakan bahasa Indonesia yang bercampur dengan bahasa daerah sunda. Untuk itu peneliti menyimpulkan bahwa siswa kurang percaya diri menggunakan bahasa Indonesia kerena tidak terbiasa. Langkah pembelajaran mendongeng sesuai kompetensi dasar 3.8 dan 4.8 di kelas III SDN I Ciparay sesuai langkah metode picture and picture dapat diuraikan sebagai berikut.

1. Guru menyampaikan kompetensi yang ingin dicapai, dalam hal ini guru menyampaikan kompetensi dasar yaitu KD 3.8 Menguraikan pesan dalam dongeng yang disajikan secara lisan, tulis dan visual (gambar/film) dengan tujuan untuk kesenangan, dan KD 4.8 memeragakan pesan dalam dongeng sebagai bentuk ungkapan diri menggunakan kosakata baru dan kalimat efektif.

2. Guru menyajikan materi sebagai pengantar, materi yang diungkapkan, yaitu mengenai materi dongeng yang meliputi pengertian dongeng, jenis dongeng, manfaat dongeng, unsur intrinsik dongeng, serta pesan atau amanat dalam dongeng. Dalam materi dongeng ini, guru juga menyisipkan bagaimana cara berbicara/mendongeng yang baik dengan memerhatikan intonasi, ketepatan kosakata/ucapan, dan bagaimana kalimat yang efektif.

3. Guru menunjukkan atau memperlihatkan gambar-gambar yang berkaitan dengan materi dongeng, dalam hal ini guru memberikan gambar tokoh dan peristiwa sesuai yang ada dalam dongeng.

4. Guru menunjuk atau memanggil siswa secara bergantian untuk memasang atau mengurutkan gambar-gambar tokoh dan peristiwa dalam dongeng menjadi urutan yang logis. Ketika memasangkan gambar, guru mengetes kemampuan mereka dalam berbicara 
menggunakan bahasa Indonesia yang efektif untuk bercerita sambil memasangkan gambar. Guru juga memberi arahan bagaimana kosakata yang tepat dan penyampaian yang tepat.

5. Guru menanyakan alasan atau dasar pemikiran urutan gambar tersebut yang disambut siswa dengan alasan yang diungkapkan menggunakan bahasa indonesia yang efektif.

6. Dari alasan atau urutan gambar tersebut, guru menanamkan konsep mengenai jalan cerita dan pesan yang terdapat dalam dongeng

7. Untuk kemudian dibuat simpulannya berupa penampilan siswa yang menyampaikan ringkasan cerita dongeng dan amanat yang bisa diambil dari dongeng tersebut. Penyampaian pesan cerita tersebut menggunakan bahasa Indonesia yang efektif, intonasi yang tepat, gesture yang tepat sesuai arahan guru pada saat pengurutan gambar-gambar tersebut.

Melalui rangkaian gambar yang ditawarkan dalam metode picture and picture, siswa menjadi tidak terbebani untuk mencapai tujuan pembelajaran. Siswa menjadi terbantu oleh gambar dalam mengungkapkan cerita dan pesan dongeng. Sehingga siswa akan fokus memilah kosakata yang tepat dan kalimat yang efektif dalam mengungkapkan pesan dongeng. Selain itu, melalui arahan guru, siswa belajar berbicara menggunakan bahasa Indonesia dalam mengungkapkan pesan dongeng dengan memerhatikan intonasi, tekanan, tempo, dan gesture. Sehingga siswa dapat memeragakan pesan dongeng dengan baik.

Penerapan metode picture and picture pada materi mengungkapkan pesan dongeng (Keterampilan berbicara) KD 3.8 dan 4.8 berjalan dengan sangat efektif dan terarah jika dibandingkan dengan penerapan metode snowball throwing di kelas kontrol. Penggunaan metode snowball throwing membuat siswa sulit dikondisikan karena terlalu semarak dan ramai. Berdasarkan hasil penilaian, diperoleh hasil bahwa siswa yang menggunakan metode picture and picture dapat dengan mudah menceritakan kembali dan mengungkapkan pesan dongeng dibandingkan dengan yang menggunkan metode snowball throwing. Hasil penilaian tersebut dapat dilihat pada Gambar 1.

Caruban: Jurnal Ilmiah Pendidikan Dasar 3(1), 67-76, Januari 2020

DOI: http://dx.doi.org/10.33603/.v3i1.3189, p-ISSN 2615-1391, e-ISSN 2620-3219

(CProdi PGSD Universitas Swadaya Gunung Jati 


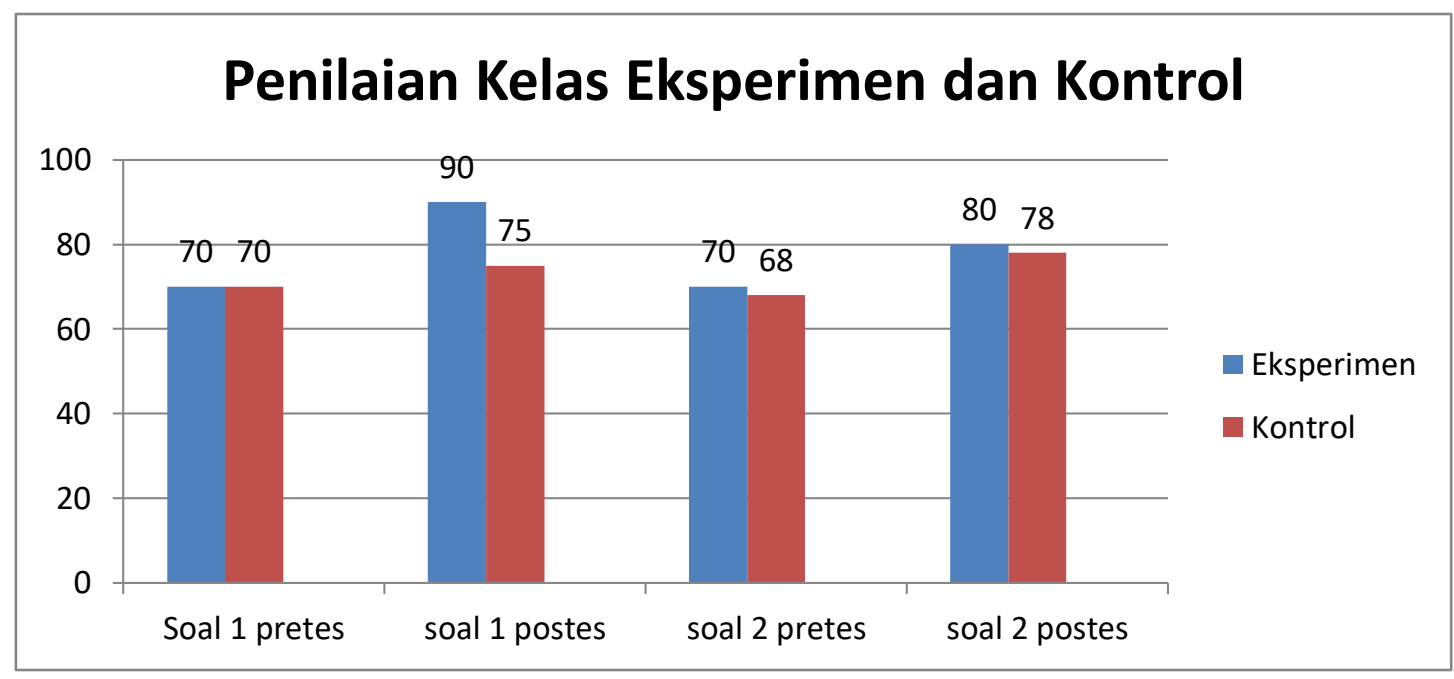

Gambar 1. Hasil Penilaian Kelas Eksperimen dan Kontrol

Berdasarkan Gambar 1 dapat diketahui bahwa berdasarkan hasil tes terhadap siswa kelas eksperimen dan kelas kontrol, soal pretes nomor satu mendapat skor nilai yang sama yakni 70. Namun setelah diberikan metode yang berbeda, kelas eksperimen yang menggunakan metode picture and picture mendapat nilai postes lebih unggul yakni 90 jika dibandingkan kelas kontrol yang mendapat nilai 75. Begitu pun pada soal tes nomor dua, siswa kelas eksperimen mendapat nilai pretes sebesar 70 dan kelas kontrol mendapat nilai 68. Namun setelah diberikan metode yang berbeda, kelas eksperimen yang menggunakan metode picture and picture mendapat nilai postes lebih unggul yakni 80 jika dibandingkan kelas kontrol yang mendapat nilai 78.

\section{Simpulan dan Rekomendasi}

Berdasarkan hasil penelitian diketahui bahwa penerapan metode picture and picture pada materi mengungkapkan pesan dongeng (Keterampilan berbicara) KD 3.8 dan 4.8 berjalan dengan sangat efektif dan terarah jika dibandingkan dengan penerapan metode snowball throwing di kelas kontrol. Penggunaan metode snowball throwing membuat siswa sulit dikondisikan karena terlalu semarak dan ramai. Melalui rangkaian gambar yang ditawarkan dalam metode picture and picture, siswa menjadi tidak terbebani untuk mencapai tujuan pembelajaran. Siswa menjadi terbantu oleh gambar dalam mengungkapkan cerita dan pesan dongeng. Sehingga siswa akan 
fokus memilah kosakata yang tepat dan kalimat yang efektif dalam mengungkapkan pesan dongeng. Selain itu, melalui arahan guru siswa belajar berbicara menggunakan bahasa Indonesia dalam mengungkapkan pesan dongeng dengan memerhatikan intonasi, tekanan, tempo, dan gesture. Sehingga siswa dapat memeragakan pesan dongeng dengan baik. Begitupun dengan hasil tes kelas eksperimen dan kelas kelas kontrol yang menunjukkan bahwa kelas eksperimen mendapat nilai yang lebih baik dibandingkan kelas kontrol. Hal ini menunjukkan bahwa metode picture and picture dapat meningkatkan kemampuan keterampilan berbicara anak SD terutama materi mengungkapkan pesan dongeng menggunakan kosakata baru dan kalimat efektif.

Dalam perjalanan penelitian, penulis menemui beberapa kendala, diantaranya, sulitnya siswa yang terbiasa berbahasa daerah dalam pergaulan sehari-hari dalam berdaptasi dengan bahasa Indonesia. Untuk itu, penulis dapat merekomendasikan agar guru dalam lingkungan sekolah mampu membiasakan siswanya berbahasa Indonesia sebagai sarana latihan agar siswa mampu memiliki kemampuan berbicara dalam bahasa Indonesia.

\section{Daftar Pustaka}

Arifin, Zaenal dan Amran Tasai. 2004. Cermat Berbahasa Indonesia. Jakarta : Akademika Pressindo.

Arsjad, Maidar G. dan Mukti U.S. 1991. Pembinaan Kemampuan Berbicara Bahasa Indonesia. Jakarta: Erlangga.

Hamdani. 2011. Strategi Belajar Mengajar. Bandung : Pustaka Setia.

Haryadi. 1994. Pengantar Berbicara. Yogyakarta : IKIP Yogyakarta.

Sugiarto, Eko. 2015. Mengenal Sastra Lama. Yogyakarta : Andi.

Sugiyono. 2008. Metode Penelitian Kuantitatif Kualitatif dan R E D. Bandung: Alfabeta.

Tarigan, Henry Guntur. 1990. Berbicara Sebagai Suatu Keterampilan Berbahasa. Cetakan ke-6 Bandung: Angkasa. 